\title{
Basic Research and Clinical Application of Drug Delivery Systems for the Treatment of Age-Related Macular Degeneration
}

\author{
Giuseppe Lo Giudice and Alessandro Galan \\ San Paolo Ophthalimc Center, San Antonio Hospital
}

Italy

\section{Introduction}

The eye is in specific environment to resist pharmaceutical approaches. Vitreoretinal diseases, including age-related macular degeneration (AMD) (Green \& Enger, 1993; Sarks, 1976; van der Schaft et al., 1992), are refractory to both topical and systemic pharmacological approaches because of specific environment of the eye. More recently, a variety of pharmacological challenges to treat exudative age-related macular degeneration and macular edema are proceeding into clinical trials, as soon as antivascular endothelial growth factor (anti-VEGF) therapies have been proved to be effective by repeated intravitreal injections. Monthly injections of anti-VEGF therapies to maximize visual potential are a significant treatment burden on the patient. As a result, the need for better treatments for AMD remains (Brown et al., 2006; Geroski \& Edelhauser, 2000; Hughes, 2005; Rosenfeld et al., 2006) (Figure 1).

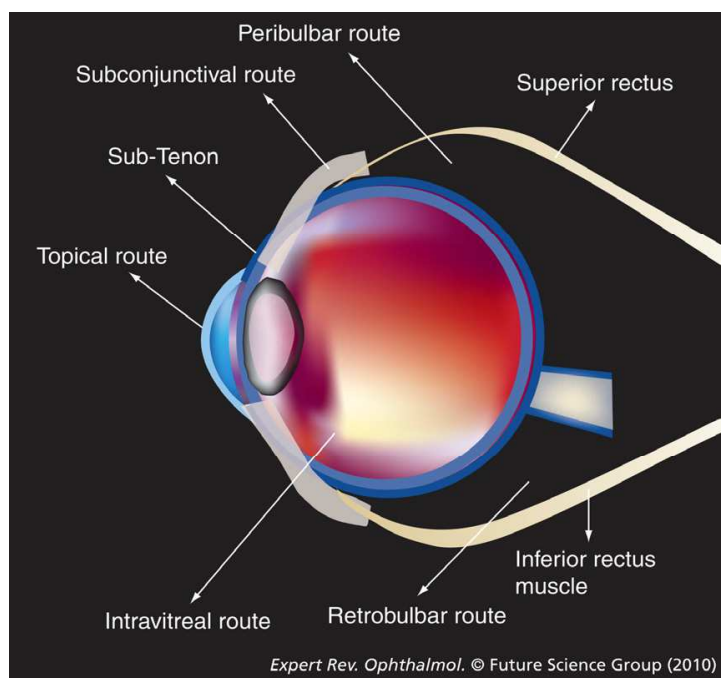

Fig. 1. Different methods of drug delivery 
Opthalmic drug delivery is one of the most interesting and challenging endeavors facing the pharmaceutical scientist. A significant challenge to the formulator is to circumvent the protective barriers of the eye without causing permanent tissue damage. Development of newer, more sensitive diagnostic techniques and novel therapeutic agents continue to provide ocular delivery systems with high therapeutic efficacy. The goal of pharmacotherapeutics is to treat a disease in a consistent and predictable fashion. The efficacy of a compound is governed by its intrinsic effects on the target site (and any other sites with which it comes into contact), its distribution throughout and its elimination from the body. Alterations to the and elimination of a compound can thus radically alter its efficacy. For regions of the body with a significant barrier to drug permeation, such as the eye and brain, great care should be taken to deliver drugs appropriately (Figure 2).

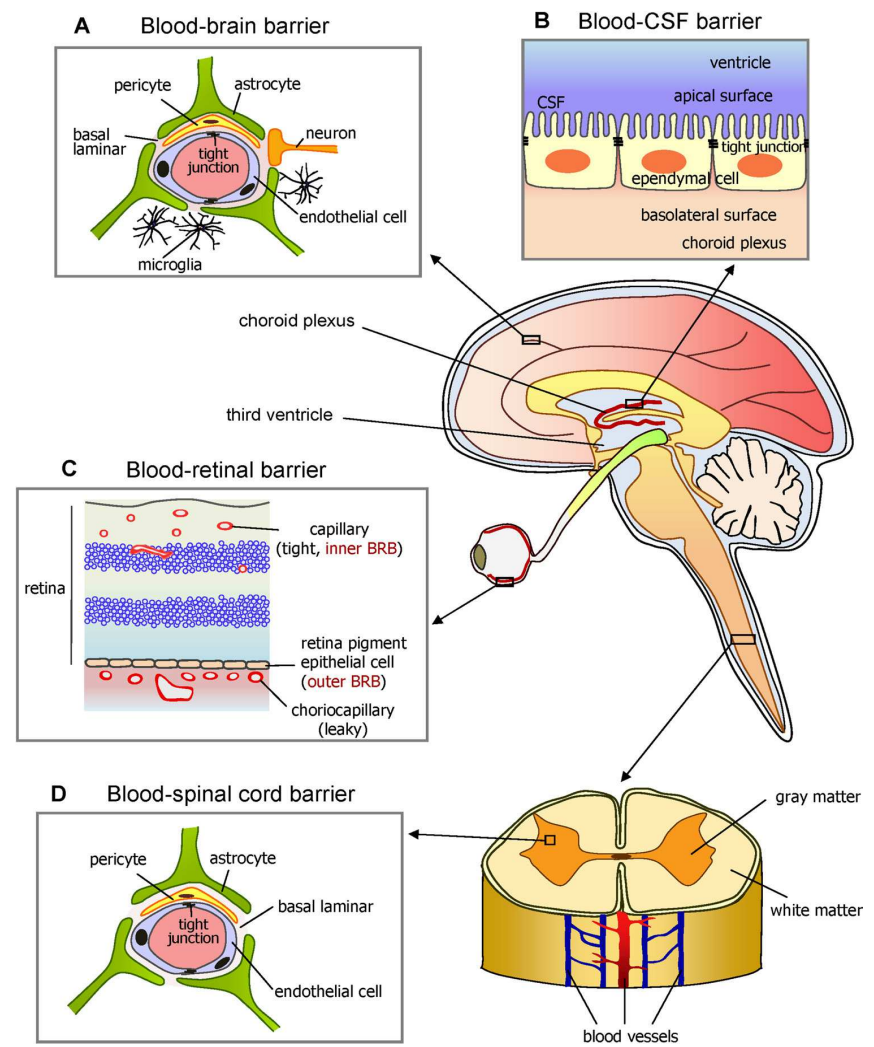

Fig. 2. Diagram of the brain and spinal cord. Diagram of the brain and spinal cord illustrating how the eye's inner and outer blood-retinal barriers (BRBs) fit into the overall scheme of blood-neural barriers (BNBs) Barriers between the blood and neural tissues are collectively referred to as BNBs and include the blood-brain barrier (A), the blood-CSF barrier (B), the BRB (C), and the blood-spinal cord barrier (D). Considering that several retinal disorders are accompanied by dysfunction or breakdown of this BRB and their associated cell-cell signaling mechanisms, elucidating the nature of the BRB is important for under standing normal health and disease (Choi \& Kim, 2008). 
In the design of a drug delivery system for the eye a balance must be struck between the limitations imposed by the physicochemical properties of the drugs, the limitations imposed by the anatomy and disease state of the eye, and the dosing requirements of the drug for that particular disease. In the recent past years review articles have focused on drug delivery to the eye (Acharya \& Young 2004; Andreoli \& Miller, 2007; Barar, Javadzadeh \& Omidi, 2008; Barocas \& Balachandran 2008; Bekeredjian, Katus \& Kuecherer, 2006; Booth et al. 2007; Del Amo \& Urtti, 2008; Gaudana et al. 2009; Hoffman, 2008; Hsu, 2007; Lee \& Robinson, 2009; Lemley \& Han, 2007; Liu \& Regillo, 2004; Mitra, 2009; Novack, 2009; Sultana et al., 2006). The aim of this chapter is to emphasize recent advances in ocular drug delivery techniques most suitable for AMD.

\section{Ocular delivery systems}

\subsection{Ocular barriers}

The eye is in specific environment to resist pharmaceutical approaches (Maurice \& Mishima, 1984). Systemically administered drug cannot easily reach the retina and vitreous cavity due to the blood-aqueous barrier, composed of ciliary non-pigmented epithelium and iridal vascular endothelium with tight junction (TJ) and the outer and inner BRB, which are formed by the retinal pigment epithelium (RPE) and retinal vascular endothelium, respectively. On the other hand, an eyeball is covered with collagenous walls (e.g. cornea and sclera) and epithelial and endothelial barriers (e.g. cornea and RPE). These barriers, continuous tear drainage, frontward flow of aqueous humor, and surrounding blood circulations limit the penetration of administered drug (e.g. eye drops and ointments) (Figure 3)

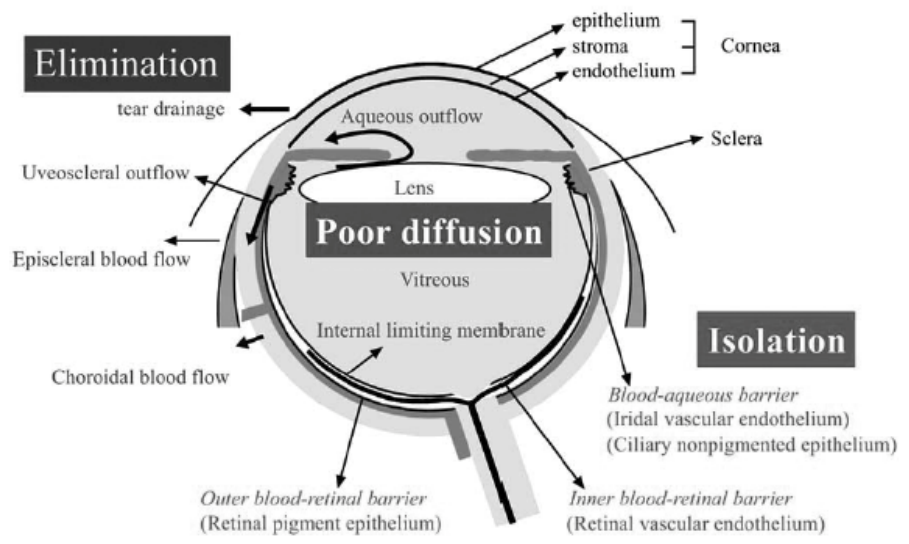

Fig. 3. Possible barriers interfering drug delivery into the eye (Tsutomu, Yasuhiko \& Hideya et al. 2011)

Compliance is also problematic, particularly among patients who have chronic diseases such as glaucoma and refractory chorioretinal diseases, including uveitis, macular edema, neovascular (wet) and atrophic (dry) AMD, and retinitis pigmentosa. In this section, the function of ocular barrier systems is briefly described (Table 1). 


\begin{tabular}{|c|c|c|c|c|c|}
\hline $\begin{array}{l}\text { Drug } \\
\text { Delivery } \\
\text { Mode } \\
\end{array}$ & $\begin{array}{l}\text { Intravitreal } \\
\text { Injection }\end{array}$ & $\begin{array}{l}\text { Sub-Tenon's } \\
\text { Injection }\end{array}$ & $\begin{array}{l}\text { Suprachoroidal/Intrascleral } \\
\text { Hollow Microneedle } \\
\text { Injection }\end{array}$ & Topical Drops & $\begin{array}{l}\text { Systemic Oral } \\
\text { Pills }\end{array}$ \\
\hline $\begin{array}{l}\text { Pathway to } \\
\text { target } \\
\text { posterior } \\
\text { segment } \\
\end{array}$ & Direct & Transscleral & Transchoroidal & $\begin{array}{l}\text { Transconjunctival/ } \\
\text { transscleral }\end{array}$ & Trans-RPE \\
\hline \multicolumn{6}{|l|}{ Safety } \\
\hline Risk & $\begin{array}{l}\text { Highest } \\
\text { injection risk }\end{array}$ & $\begin{array}{l}\text { Highest } \\
\text { injection risk, } \\
\text { mild systemic } \\
\text { exposure }\end{array}$ & $\begin{array}{l}\text { Minimal injection risk, } \\
\text { minimal systemic exposure }\end{array}$ & $\begin{array}{l}\text { Safest, but moderate } \\
\text { systemic exposure }\end{array}$ & $\begin{array}{l}\text { Minimal local } \\
\text { exposure; } \\
\text { highest } \\
\text { systemic } \\
\text { exposure }\end{array}$ \\
\hline $\begin{array}{l}\text { Adverse } \\
\text { Events }\end{array}$ & \begin{tabular}{|l|} 
Vitreous \\
hemorrhage, \\
retinal \\
detachment, \\
endophthalmitis \\
\end{tabular} & $\begin{array}{l}\text { Subconjunctival } \\
\text { hemorrhage }\end{array}$ & $\begin{array}{l}\text { Subconjunctival } \\
\text { hemorrhage, } \\
\text { suprachoroidal } \\
\text { hemorrhage }\end{array}$ & $\begin{array}{l}\text { Conjunctival redness } \\
\text { and irritation }\end{array}$ & $\begin{array}{l}\text { Gastrointestinal } \\
\text { upset }\end{array}$ \\
\hline Efficacy & $\begin{array}{l}\text { Most direct and } \\
\text { effective } \\
\text { (only mode } \\
\text { that directly } \\
\text { penetrates BRB) }\end{array}$ & $\begin{array}{l}\text { Much less } \\
\text { bioavailable to } \\
\text { the vitreous } \\
\text { and retina }\end{array}$ & $\begin{array}{l}80 \text {-fold more bioavailable } \\
\text { than } \\
\text { sub-Tenon's injection }\end{array}$ & $\begin{array}{l}\text { Worst bioavailability } \\
\text { and second worst } \\
\text { duration of action; } \\
\text { convenient and } \\
\text { can be self- } \\
\text { administered } \\
\text { at home }\end{array}$ & $\begin{array}{l}\text { Second worst } \\
\text { bioavailability } \\
\text { and worst } \\
\text { duration of } \\
\text { action }\end{array}$ \\
\hline \multicolumn{6}{|l|}{$\begin{array}{l}\text { Peak } \\
\text { bioavailability }\end{array}$} \\
\hline Intravitreal & $100 \%$ & $0.01 \%-0.1 \%$ & $0.8 \%-70 \%$ & $0 \%-0.0004 \%$ & $0 \%-2 \%$ \\
\hline $\begin{array}{l}\text { Intra-aqueous } \\
\text { humor }\end{array}$ & $3 \%$ & $0.008 \%-0.8 \%$ & $0.02 \%-2.1 \%$ & $0.0007 \%-5 \%$ & $1 \%-2 \%$ \\
\hline $\begin{array}{l}\text { Duration of } \\
\text { action }\end{array}$ & $\begin{array}{l}21 \text { Hours to } 7 \\
\text { weeks }\end{array}$ & $\begin{array}{l}6 \text { Hours to } 1 \\
\text { month }\end{array}$ & 18 Hours to 3 months & 30 Minutes to 4 hours & $<30$ Minutes \\
\hline
\end{tabular}

Table 1. Drug delivery routes for Age-related macular de generation

\subsection{Tear, cornea, conjunctiva and sclera}

Tear: One of the precorneal barriers is tear film which reduces the effective concentration of the administrated drugs due to dilution by the tear turnover (approximately $1 \mu \mathrm{L} / \mathrm{min}$ ), accelerated clearance, and binding of the drug molecule to the tear proteins (Craig, 2002).

Cornea: The cornea consists of three layers; epithelium, stroma and endothelium, with each one possessing a different polarity, rate-limiting structure for drug penetration and a mechanical barrier to inhibit transport of exogenous substances into the eye (Pederson, 2006). The corneal epithelium is characterized by tight junctions among cells; these are formed to restrict paracellular drug permeation from the tear film. The highly hydrated structure of the stroma (extracellular matrix of a lamellar arrangement of collagen fibrils) acts as a barrier to permeation of lipophilic drug molecules. Corneal endothelium acts as a separating barrier between the stroma and aqueous humor (Fischbarg, 2006). .

Conjunctiva: Conjunctiva or episclera has a rich supply of capillaries and lymphatics therefore, administrated drugs in the conjunctival or episcleral space may be cleared 
through blood and lymph (Gausas, Gonnering, Lemke, et al. 1999; Singh, 2003; Sugar, Riazi, \& Schaffner, 1957). The conjunctival blood vessels do not form a TJ barrier which means drug molecules can enter into the blood circulation by pinocytosis and/or convective transport through paracellular pores in the vascular endothelial layer. The conjunctival lymphatics act as an efflux system for the efficient elimination from the conjunctival space. Drugs transported by lymphatics in conjunction with the elimination by blood circulation can contribute to systemic exposure, since the interstitial fluid is returned to the systemic circulation after filtration through lymph nodes (Lee, He, Robinson, et al. 2010).

Slera: Scleral permeability has been shown to have a strong dependence on the molecular radius (it consists of collagen fibers and proteoglycans embedded in an extracellular matrix); scleral permeability decreases roughly exponentially with molecular radius (Oyster, 1999). The ideal location for transscleral drug delivery is near the equator at $12-17 \mathrm{~mm}$ posterior to the corneoscleral limbus. Hydrophobicity of drugs affects scleral permeability; increase of lipophilicity shows lower permeability; and hydrophilic drugs may diffuse through the aqueous medium of proteoglycans in the fiber matrix pores more easily than lipophilic drugs.

\subsection{Choroid/Bruch's membrane and retina}

Choroid/Bruch's Membrane: Choroid is one of the most highly vascularized tissues of the body. The choroidal capillary endothelial cells are fenestrated and, are relatively large in diameter $(20-40 \mu \mathrm{m})$. Previous histological studies have shown choroidal thickness changes from $200 \mu \mathrm{m}$ at birth decreasing to about $80 \mu \mathrm{m}$ by age 90 (Spaide, 2009). In contrast, Bruch's membrane (BM) causes thickening with age (Tout, Chan-Ling, Hollander, et al. 1993). These changes cause increased calcification of elastic fibers, increased cross-linkage of collagen fibers and increased turnover of glycosaminoglycans. Thickness changes of choroid and BM might affect drug permeability from subconjunctiva or episcleral space into the retina and the vitreous (Farboud, Aotaki-Keen, Miyata, et al. 1999; Handa, Verzijl, Matsunaga, et al. 1999; Hewitt, Nakazawa \& Newsome, 1989; Hewitt \& Newsome, 1985; Spraul, Lang, Grossniklaus, H.E. et al. 1999; Tout, Chan-Ling, Hollander, et al. 1993; Yamada, Ishibashi, Bhutto, et al. 2006).

Retina: in the vitreous drugs are eliminated by two main routes from anterior and posterior segments. Elimination via the posterior route takes place by permeation across the retina. In intact retina, the drugs in the subretinal fluid could either be absorbed by the sensory retinal blood vessels or transported across the RPE, where it may be absorbed into the choroidal vessels or pass through the sclera. Drug transport across the RPE takes place both by transcellular and paracellular routes. The driving forces of outward transport of molecules from the subretinal spaces are hydrostatic and osmotic, and small molecules might transport through the paracellular inter-RPE cellular clefts and by active transport through the transcellular route (Pederson, 2006).

\subsection{Blood retinal barrier}

The BRB controls the flux of fluid and blood-borne elements into the neural parenchyma, helping to establish the unique neural environment necessary for proper neural function. 
BRB restricts drug transport from blood into the retina. BRB is composed of tight junctions (TJ) of retinal capillary endothelial cells and RPE, called iBRB for the inner and oBRB for the outer BRB, respectively. The function of iBRB is supported by Müller cells and astrocytes (Cunha-Vaz, 1979).

Müller cells are known to support neuronal activity and maintain the proper functioning of the iBRB under normal conditions.The astrocytes are closely associated with the retinal capillary vessels and help to maintain the capillary integrity (Zhang \& Stone, 1997). Astrocytes are known to increase the barrier properties of the retinal vascular endothelium by enhancing the expression of the tight junction protein ZO-1 and modifying endothelial morphology (Gardner, Lieth, Khin, et al. 1997).

Following systemic drug administration, drugs can easily enter into the choroid since choroid is highly vascularized tissue compared to retina. The choriocapillaris are fenestrated resulting in rapid equilibration of drug molecules present in the bloodstream with the extravascular space of the choroid. Therefore, oBRB (RPE) restricts further entry of drugs from the choroid into the retina. RPE is a monolayer of highly specialized hexagonal-shaped cells, located between the sensory retina and the choroid. The TJ of the RPE efficiently restrict intercellular permeation into the sensory retina. Dysfunction of Müller cells may contribute to a breakdown of the iBRB in many pathological conditions (Tretiach, Madigan, Wen, et al. 2005). Müller cells enhance the secretion of VEGF under hypoxic and inflammatory conditions (Eichler, Kuhrt, Hoffmann, et al. 2000; Kaur, Sivakumar \& Foulds, 2006). VEGF-induced occluding phosphorylation and ubiquitination causes trafficking of tight junction and leads to increased retinal vascular permeability (Murakami, Felinski \& Antonetti, 2009).

\section{Drug delivery systems to posterior segment of the eye and specific delivery systems}

In drug delivery, a more common situation is one where the rate of change of concentration is directly proportional to the concentration of drug present, and drug's potential to diffuse from one region to another is directly proportional to its chemical potential, which can usually be approximated to its concentration. This situation is termed first order and can be expressed as (Higuchi, 1961)

$$
-\mathrm{dc} / \mathrm{dt}=\mathrm{kc}
$$

where $\mathrm{dc}$ is the change in concentration, $\mathrm{dt}$ is the time interval over which that change occurs, $\mathrm{k}$ is a constant, also known as the rate constant, and it is in function of concentration.

Integrating this with respect to time gives (Peppas, 1995)

$$
\ln \mathrm{C}_{\mathrm{t}}-\ln \mathrm{C}_{0}=-\mathrm{kt}
$$

where $C_{0}$ is the initial concentration and $C_{t}$ is the concentration at time $t$.

A more common situation arises when drug release is both a function of its concentration within a vehicle and its ability to diffusion through it. When placed into a release medium, the drug closest to the surface is released the fastest. Over a period of time, the drug must 
diffuse from further and further back within the bulk of the device, which progressively slows the release.

Systems such as this can be described by solutions to Ficks's second law of diffusion (Knight, 1981)

$$
\partial \mathrm{C} / \partial \mathrm{t}=\mathrm{D} \partial^{2} \mathrm{C} / \mathrm{dx} \mathrm{x}^{2}
$$

where $\mathrm{C}$ is the concentration in a reservoir, $\mathrm{t}$ the time, $\mathrm{x}$ the distance and $\mathrm{D}$ the diffusion coefficient the diffusant through the media. Partial derivatives $(\partial)$ are used because $C$ is a function of both $t$ and $x$.

These formulae can be readily applied to drug release from ointments and gels typically used in eye drops, but an objective difficulty exist in finding a flawless technique to deliver drugs targeting diseases that directly affect the retina and vitreous humor, owing to the anatomic barriers and physiologic clearance mechanisms of the BRB. In this scenario a relevant implication have the importance of the transcellular and paracellular transport pathways across or between epithelial or endothelial BRBs. TJs are the most apical component of both the epithelial or endothelial intercellular junctional complexes. TJs are crucial for the formation and maintenance of epithelial and endothelial paracellular barriers since they semipermeably regulate intercellular passive diffusion of large or hydrophilic ions and solutes. Moreover, a complex network of TJ proteins have been identified, with the assembly and dynamic maintenance of various claudin proteins being the most crucial in regard to dictating the selectivity of this paracellular barrier. Using the transcellular route, drugs are delivered by simple passive diffusion to bind with cell surface membrane-bound transporters (cell surface receptors, pumps, channels, and transporters) where they can directly cross the cell via passive diffusion again or through active transport mechanisms. Various influx and efflux transporters have been found for small lipophilic peptides, organic anions, and cations. Transporter-mediated drug delivery is tissue-specific and has low toxicity since transmembrane concentration gradients are not required for it works. The transcellular pathway is not suitable for high-throughput production of drug candidates though, unlike the paracellular pathway, which is suitable for highthroughput production since drug modification is not needed and one method can be applied for various drugs. Knowing the rate-limiting tissue barrier based on the physiochemical properties of a drug helps when optimizing the absorption of passively penetrated drugs.

\subsection{Intravitreal injections and intraocular drug delivery}

Intraocular drug delivery is the only mode that currently directly broaches the BRB and thereby attains the highest peak intravitreal or intraretinal drug concentrations. However, intraocular drug delivery is the most invasive than other approaches, in that it involves penetrating the globe and thus is not free of injection-related complications. These complications may include trauma and increased risk of cataract, retinal detachment, hemorrhage and endophthalmitis (Jager, Aiello, Patel, et al. 2004).

Moreover, the presence of some moderate clearance mechanisms (posterior transretinal and anterior aqueous humor elimination pathways) cause the peak drug concentration levels achieved with intraocular administration to decline to non-therapeutic trough levels over 
time, unless the injections are given frequently and repeatedly. The disadvantage caused by the short to medium duration of action of intravitreal drug solutions has been partially alleviated through product formulation or drug device development. Currently, despite its shortcomings, intravitreal administration is the preferred drug delivery route to treat diseases of the posterior segment being the better approach achieving the highest intraocular bioavailability in posterior segment tissues such as the cone-containing macula or fovea.

Anti-VEGF drugs, such as pegaptanib, ranibizumab and bevacizumab are new intravitreal treatments for AMD. To understand the pharmacokinetics of intravitreal drug delivery a great attention should be made to understanding the molecular structure of the normal human vitreous gel and that normal vitreous gel undergoes age-related degenerative liquefaction. It was shown that immediately after intravitreal injection, drugs initially concentrate near the injection site or in the cisternae forming vitreous concentration gradients before distributing throughout the entire vitreous cavity and then reaching steady state equilibrium levels (Lee SS, et al. IOVS 2009;50:ARVO E-Abstract 5950). The location of implant placement in the vitreous (anterior placement behind lens versus posterior placement near the retina) influences drug levels in various tissues. When the implant was placed in the posterior region, drug levels were higher in the posterior retina, choroid-RPE and sclera and lower in the anterior retina, choroid-RPE, and sclera. Posterior placement of the implant is likely to support release of the drug to target tissues in case of retinal disorders. Although the posterior implant reduced drug levels in the lens, no such advantage was found with respect to corticosteroid levels in the trabecular meshwork, possibly due to the high affinity of the drug for this tissue.

After intravitreal placement of an implant, drug levels are not likely to achieve a uniform level throughout the vitreous. However, it is probable that a slow release system achieves zones of steady state concentration, with the contours dictated by the clearance mechanisms of a given therapeutic agent. The reason for such zones or contours of steady state concentration is not necessarily diffusion limitation, but rather the presence of continuous dynamic clearance mechanisms in the posterior segment. There are two main mechanisms of drug clearance for intravitreally administered drugs in the eye: the anterior elimination pathway via counterdirectional bulk aqueous flow and the posterior elimination pathway via vitreoretinochoroidal bulk flow due to hydrostatic and osmotic pressure gradients in the inner, middle, and outer coats of the posterior segment (Kim, Lutz, Wang, et al. 2007). An additional mechanism to consider is the transcellular carrier-mediated transporters found on the RPE. Influx transporters enhance the penetration of drugs and efflux transporters inhibit retention of drugs across the outer (o)BRB (Mannermaa, Vellonen \& Urtti, 2006). The duration of action of an intravitreally administered drug may in part depend on the retention of the injected drug at the site of administration. The longer the intravitreal halflife, the greater the anticipated duration of therapeutic response. The half-lives of drugs that are eliminated through both the retina and the aqueous humor, such as small lipophilic drugs, tend to be shorter than the half-lives of drugs eliminated primarily via the anterior route, such as large hydrophilic drugs, and also intravitreal drug elimination depends on the molecular weight (MW) of the drug, with larger MW $(>70,000)$ drugs displaying longer half-lives. To overcoming the short to medium duration of action of intravitreal drug solutions is the use of one of several available sustained drug release systems. These systems 
may act through formulation modification to decrease the solubility of the drug via a suspension or to enhance the residence time in vitreous humor via a biodegradable implant, or through the use of a sustained release delivery device.

\subsection{Non-biodegradable, biodegradable implants in AMD}

Non-biodegradable implants are a reservoir type, which possesses a coating of nonbiodegradable polymers such as poly (vinyl alcohol) (PVA), ethylene vinyl acetate (EVA), and silicone laminate, reserving drug in the inner space. This type exhibits the most stable and long-standing release profile of drug, as compared with other types of implants, because it can reserve a large amount of drug and regulate drug release just by surface area and thickness of PVA, a permeable polymer (Okabe, Kimura, Okabe, et al. 2003; Yasukawa, Ogura, Kimura, et al. 2006; Yasukawa, Ogura, Tabata, et al. 2004). However should be considered the weakness of this type of device involving relatively large size of the device requiring a large incision for implantation, which may increase the risk of retinal complications (vitreous hemorrhage, epiretinal membrane, and retinal detachment), and potential need of removal surgery to exchange the implant or treat possible complications such as retinal detachment and drug-induced adverse effects (Callanan, 2007). As compared with non-biodegradable implants, biodegradable implants have following merits: no need of removal surgery and the flexibility in shape. They can be processed into a variety of configurations involving microparticles, a rod, a disc, or tablet. Thus, the release profile of drug from this 2nd generation biodegradable implants may become as stable as nonbiodegradable ones, while the duration of drug release may be shorter due to the limitation of drug contained. The drugs in the biodegradable implants are conjugated to a variety of polymers including poly(lactic acid) (PLA), poly(glycolic acid) (PGA), poly(lactic-co-glycolic acid) (PLGA), poly(caprolactone) and poly(methylene malonate) (table 2).

\begin{tabular}{|l|l|l|l|l|}
\hline Active ingredient & Brand name & Dosage form & $\begin{array}{l}\text { Release-controlling } \\
\text { excipient }\end{array}$ & target indication \\
\hline $\begin{array}{l}\text { fluocinolone } \\
\text { acetonide }\end{array}$ & illuvien ${ }^{\circledR}$ & IVT, implant & Polyimide/PVA & wet AMD, DME \\
\hline Brimonidina & - & IVT, implant & PLGA & Dry AMD, RP \\
\hline $\begin{array}{l}\text { CNTF } \\
\text { (NT-501) }\end{array}$ & - & IVT, implant & $\begin{array}{l}\text { semipermeabile } \\
\text { membrane/ARPE-19 }\end{array}$ & RP, dry AMD \\
\hline
\end{tabular}

Table 2. Current and future drugs in clinical trials for posterior disease (AMD)

The ongoing clinical trial clearly indicates that biodegradable polymers are biocompatible. In the near future, many types of biodegradable implants and microparticles will proceed for clinical trial.

An injectable, rod-shaped intravitreal implant with FA (Iluvien ${ }^{\circledR}$, Alimera Sciences, Alpharetta, GA, U.S.) (length: $3.5 \mathrm{~mm}$, diameter: $0.37 \mathrm{~mm}$ ) has been developed for the treatment of diabetic macular edema (DME). Iluvien ${ }^{\circledR}$ is made of polyimide and PVA, small enough to be injected using an inserter with a 25-gauge needle and is expected to provide sustained delivery of FA to the back of the eye for up to three years. In addition to DME, Iluvien ${ }^{\circledR}$ is in Phase II for the treatment of wet AMD compared to Lucentis ${ }^{\circledR}$ 
(ClinicalTrials.gov The MAP Study: Fluocinolone acetonide (FA)/MedidurTM for age related macular degeneration (AMD) Pilot. (2010). Available online: http://clinicaltrials.gov/ct2/show/ NCT00605423?term=Iluvien\&rank=12), dry AMD (ClinicalTrials.gov Fluocinolone acetonide intravitreal inserts in geographic atrophy. (2010). Available online: http://clinicaltrials.gov/ct2/show/NCT00695318?term=Iluvien\&rank=15.

Brimonidine is an a2 adrenergic agonist, which can release various neurotrophins including brain-derived neurotrophic factor (BDNF) and ciliary neurotrophic factor (CNTF) (Lonngren, Napankangas, Lafuente, et al. 2006; Kim, Chang, Kim, et al. 2007). These neurotrophins have a potential to prevent apoptosis of photoreceptors and/or RPE (Azadi, Johnson, Paquet-Durand, et al. 2007; Zhang, Mo, Fang, et al. 2009). PLGA intravitreal implant with two doses $(200 \mathrm{mg}, 400 \mathrm{mg}$ ) of brimonidine tartrate similar to Ozurdex® is now in Phase II clinical study for dry AMD (ClinicalTrials.gov Safety and efficacy of brimonidine intravitreal implant in patients with geographic atrophy due to age-related macular degeneration (AMD). (2010). Available online: http://clinicaltrials.gov/ct2/show/NCT00658619), and phase I/II clinical trials for RP (ClinicalTrials.gov An exploratory study to evaluate the safety of brimonidine intravitreal implant in patients with retinitis pigmentosa. (2010). Available online: http://clinicaltrials.gov/ct2/show/ NCT00661479) by Allergan, Inc. Neurotech Pharmaceuticals, Inc. (Lincoln, RI, U.S.) has been developing -"Encapsulated Cell Technology", this is an implantable intravitreal device that uses genetically modified ARPE19 RPE cells (transfected with plasmid gene insertion techniques) to release a therapeutic growth factor protein, ciliary neurotrophic factor (CNTF), with zero-order kinetics. CNTF is a neurotrophic growth factor with profound antiapoptotic effects that prolong the lives of dying photoreceptor cells. The cells are encapsulated within a semipermeable, hollow-fiber membrane, intravitreal implant device so that the CNTF protein is released to ocular tissues but the modified RPE cells are immunologically isolated from the patient, avoiding immune rejection. Phase 2 trials showed that this delivery system was safe, and a dose-dependent biological effect on the retina was observed. Potential visual benefit was also shown in patients with geographic atrophy (US National Institutes of Health. ClinicalTrials.org. NCT00447954 CgI. A Study of an Encapsulated Cell Technology (ECT) Implant for Patients With Atrophic Macular Degeneration. Phase II study. (2009). http://clinicaltrials.gov/ct2/show/NCT00447954). The duration of action of this encapsulated cell therapy device was found to be up to 2 years. Next-phase clinical trials are under way to continue to evaluate encapsulated cell technology (ECT)-CNTF's effectiveness for the treatment of dry AMD and retinitis pigmentosa.

Anti-VEGF compounds are now required to be administered into the eye every 4 to 6 weeks. Moreover, vitrectomized eyes highly increase the clearance rate of injected drugs and are, therefore, refractory to these drugs. The companies are currently interested in new methods of prolongation of residence time of intravitreally-injected drugs such as ranibizumab and pegaptanib. Viscous medium such as hyaluronic acid or gelling solution are considered as an additive to prolong drug residence in the vitreous cavity (Table 3) (Lyons, Ma \& Trogde, 2009; Giese, Kaufmann \& Klippel-Giese, 2004; McSwiggen, Beigelman, Macejak, et al. 2003; Robinson, Blanda, Hughes, et al. 2010; Robinson, Blanda, Liu, et al. 2010; Robinson, Tsai, Almazan, et al. 2010). 


\begin{tabular}{|l|l}
\hline \multicolumn{1}{c|}{ Patent No. } & \multicolumn{1}{c}{ Activity } \\
\hline WO2003070918 & Technology of siRNA modification to improve biological stability \\
\hline WO2004015107 & Technology of siRNA modification to improve biological stability \\
\hline US20100015158 & $\begin{array}{l}\text { Intraocular delivery of anti-angiogenic antibodies in a liquid or solid } \\
\text { polymeric vehicle such as hyaluronic acid or PLGA }\end{array}$ \\
\hline WO2010009034 & $\begin{array}{l}\text { Intraocular delivery of anti-angiogenic antibodies in a liquid or solid } \\
\text { polymeric vehicle such as hyaluronic acid or PLGA }\end{array}$ \\
\hline US20100098772 & Delivery of anti-angiogenic agents with polymeric hyaluronic acid \\
\hline US20100074957 & Injectable intraocular drug delivery system by use of microspheres \\
\hline US20090258924 & Intraocular delivery of siRNA with a polymeric component \\
\hline
\end{tabular}

Table 3. List of Patents on Intraocular Drug Delivery Systems

\subsection{Periocular dug derlivery route in AMD}

Periocular delivery includes such avenues as subconjunctival, retrobulbar, peribulbar, subTenon's and intrascleral delivery. This route requires drugs to pass through several layers of ocular tissue (episclera, sclera, choroid, Bruch's membrane, and RPE) to reach the retina or vitreous humor. Current knowledge shows that the combined effects of several static anatomic barriers and dynamic clearance mechanisms generally make periocular drug delivery one of the least effective ways of attaining high peak therapeutic intraocular drug concentrations in the retina or vitreous. These barriers are categorized into three major groups: static, dynamic and metabolic. Static barriers include the tissues that must be penetrated (e.g., sclera, Bruch's membrane-choroid and RPE). Dynamic barriers include blood flow, lymphatic drainage, transport proteins of the RPE, drug efflux pumps, organic ion transporters and bulk fluid flow from intraocular drainage systems. Metabolic barriers include enzyme systems such as cytochrome P450 and lysosomal enzymes, which have the ability to degrade or detoxify drugs. In addition to the static, dynamic and metabolic barriers, other factors must be considered in periocular delivery such the individual pharmacokinetic properties of the drug (molecular dimensions, molecular weight, atomic charge and chemical components of the drug). Taken together these factors result in low intraocular bioavailability of drug delivered by the various periocular drug techniques, compared with that of intravitreal injection.

Overall, when the safety and efficacy of this drug delivery route is compared with that of the others for the treatment of disease in the inner coat of the posterior segment, periocular injection is one of the best for safety, and it is in the middle to low end for efficacy, after intrinsic drug properties are factored in, such as potency and exposure-response relationships. With a few modifications, this route has the greatest potential to surpass intravitreal injection as the preferred treatment option for disease of the inner coat of the eye, since it deposits drug locally immediately adjacent to the targeted tissue without being overly invasive.

A major adjuvant used to overcome the short to medium duration of action of periocular drug solutions is the development of several sustained drug release systems, whether through formulation modifications or through various sustained release drug delivery devices. Many of these options include liposomes, microspheres, and microcapsules with 
diameters of 1-1000 $\mu \mathrm{m}$, as well as nanospheres and nanocapsules with diameters of less than $1 \mu \mathrm{m}$, and biodegradable fibrin sealants (Bourges, Gautier, Delie, et al. 2003; Bu, Gukasyan, Goulet, et al. 2007; Guidetti, Azema, Malet-Martino, et al. 2008; Kearns \& Williams, 2009). Polymeric microspheres have been used to target the RPE. Moritera et al. studied the use of surface-modified polymeric microspheres to localize drugs to the RPE (Moritera, Ogura, Yoshimura, et al. 1994). Phagocytosis by RPE was tracked by incorporating fluorescent dye into PLA microspheres with the rate of phagocytosis enhanced with gelatin-precoating as compared with bare microspheres. Intracellular dye release occurred following phagocytosis and could be controlled by varying the polymer formulation of the microspheres. Tuovinen et al. studied targeting drugs to the RPE using microparticles $(11 \mu \mathrm{m}$ in diameter) produced with starch acetate, which degrades more slowly than native starch (Tuovinen, Ruhanen, Kinnarinen, et al. 2004). These microparticles could be phagocytosed and degraded within the RPE.

Nanospheres have also been used to target the RPE for sustained drug delivery. Sakurai et al. studied the intraocular kinetics of nanospheres and found that polystyrene nanospheres containing fluorescein ( $2 \mu \mathrm{m}$ in diameter) were detectable in the retina, vitreous and trabecular meshwork more than 1 month following an intravitreal injection in vivo in rabbits (Sakurai, Ozeki, Kunou, et al. 2001). Anionic nanoparticles traversed the collagen fibrils of the vitreous more readily than the cationic nanoparticles, showing potential as drug delivery vehicles for the subretinal space and the RPE. Muller cells take up the nanoparticles, possibly playing a key role in retinal penetration. Micro- and nanoparticles have potential in the field of gene therapy by functioning as nonviral vectors to enable cellular penetration, guard against degradation and maintain sustained delivery. Bejjani et al. explored the use of PLA and PLGA nanoparticles as vectors for gene transfer to a bovine and a human ARPE-19 cell line (Bejjani, BenEzra, Cohen, et al. 2005), concluding that PLGA could successfully sequester and internalize plasmids, resulting in gene expression in RPE detectable $48 \mathrm{~h}$ postinjection and maintained for 8 days. Another therapeutic approach is the inhibition of gene expression using antisense oligonucleotides, aptamers and siRNA (Fattal \& Bochot, 2006; Fattal \& Bochot, 2008; Tanito, Li, Elliott, et al. 2007). Aukunuru et al. showed that nanoparticles formulated using a PLGA (50:50) copolymer could deliver VEGF antisense oligonucleotide to the human ARPE-19 cell line, and inhibit VEGF secretion and mRNA expression (Aukunuru, Ayalasomayajula \& Kompella, 2003). In a study performed by Carrasquillo et al. (Carrasquillo, Ricker, Rigas, et al. 2003) and summarized by Moshfeghi and Peyman (Moshfeghi \& Peyman, 2005), the anti-VEGF RNA aptamer (EYE001, Macugen ${ }^{\circledR}$, OSI Pharmaceuticals, NY, USA) was incorporated into PLGA microspheres to develop a sustainedrelease inhibition of VEGF for the treatment of neovascular AMD. Transport and drug efficacy studies of micro- and nanoparticles administered via periocular injection have been also published (Amrite, Edelhauser, Singh, et al. 2008; Amrite \& Kompella, 2005; Ayalasomayajula \& Kompella, 2003; Ayalasomayajula \& Kompella, 2004; Ayalasomayajula \& Kompella, 2005; Chiang, Tung \& Lu, 2001; Saishin, Silva, Saishin, et al. 2003). In conclusion nano- and microparticles have shown great potential for expanding the arsenal of drug-delivery systems available for treating posterior segment disease. They provide sustained delivery and reduce complications that result from treatments requiring multiple injections. Transscleral delivery of anti-VEGF drugs loaded in PLA or PLGA nanoand microparticles is gaining much attention as a feasible and effective method of administration for the treatment of posterior segment disease. 


\subsection{Hybrid drug delivery in AMD}

Minimally invasive hollow and solid microneedles ( $<1 \mathrm{~mm}$ diameter) have been developed to deliver drugs into the cornea, sclera, or suprachoroidal space to avoid some of the shortcomings in safety and bioavailability with intravitreal or periocular injection. Solid, drug-coated microneedles are used for intracorneal and intrascleral drug delivery, improved bioavailability, and duration of action. Hollow microneedles are used for intrascleral and suprachoroidal delivery of a sustained-release drug depot in a tissue layer, with clearance mechanisms that are minimal or less than those in the subconjunctival or sub-Tenon's space. Microneedles allow for better retinochoroidal targeting than periocular drug delivery, because it is closer to the target tissue (Jiang, Gill, Ghate, et al. 2007; Jiang, Moore, Edelhauser, et al. 2009). A hollow microcatheter cannulation drug delivery technique has also been developed for suprachoroidal drug delivery.

It is more directly invasive than the hollow microneedle approach, but microcatheter delivery may be promising for sustained drug delivery if it can be shown that continuous infusion of drugs into the suprachoroidal space can be tolerated better than a one-time injection with a microneedle. Overall, despite being relatively new and having few longterm data, the hybrid delivery route is arguably the second best for safety (tied with periocular and just behind topical) and second best for efficacy (the best being intraocular). This ranking has not been definitively proven in clinical trials. Another drawback that has not yet been calculated is the greater expense associated with this technology.

\subsection{Topical drug delivery in AMD}

Topical application to the anterior eye has been proven successful in the treatment of diseases owing to easy access to the target site. However, the adoption of mechanisms in ensuring topical drug penetration to the posterior eye presents numerous challenges. It is difficult to predict which drugs can achieve adequate therapeutic levels in the inner coat of the posterior segment after topical drug delivery and whether penetration can be enhanced by structural modifications or a particular formulation (Ghate \& Edelhauser, 2006). Thus, experimental testing in animal models is critical. As this drug delivery route has two major shortcomings, extremely poor bioavailability to the inner coat of the posterior segment and a short duration of action, the main adjuvants are penetration enhancers and sustained-release drug delivery systems. Paracellular penetration by topical drugs can be improved by several mechanisms including: opening TJs by using preservatives in topical medications or by iatrogenic epithelial scraping; increasing drug lipophilicity through the use of prodrugs or other analogues, such as surfactants, and binding the drugs to dendrimers that use carriermediated influx transporters.

Recent research has focused on small-molecule penetration into the vitreous, with evidence that molecules with lower molecular weight have increased permeability into the posterior chamber. Molecules with higher molecular weights and superior water solubility (highly charged) may have longer half-lives than those with lower molecular weights. Thus, lower molecular-weight compounds have increased access to the posterior eye and may minimize the risk of toxicity compared with higher molecular-weight compounds, which degrade at 
slower rates. Therefore, each drug must be individually assessed and its uptake, efficiency and safety must be determined. As the list of drugs that achieve therapeutic levels in the retina and choroid after topical administration increases, it may be possible to identify structural characteristics that promote ocular penetration and to specifically design drugs and/or prodrugs accordingly. Another new technique is represented by Iontophoresis that is an old technology recently modified into a new innovative drug delivery platform. Recent clinical trials have demonstrated that iontophoresis is sufficiently safe and capable of delivering steroids to ocular tissue to some oculare disease (uveitis). It is performed by applying a small electrical current that has the same charge as the drug to create repulsive electromotive forces (Hayden, Jockovich, Murray, et al. 2006; Hughes, Olejnik, Chang-Lin, et al 2005; Myles, Neumann \& Hill, 2005).

\subsection{Systemic drug delivery routes}

There have been advances in the use of systemic medications for the treatment of ophthalmic diseases, despite several limitations related to systemic penetration of many drugs, particularly large or hydrophilic ones, into the posterior segment of the eye. Further movement from the choroid into internal ocular structures such as the retina and vitreous humor, especially of large and/or hydrophilic drugs, is restricted by the RPE (oBRB) and TJs of the retinal vasculature (iBRB). Small lipophilic drugs, however, can penetrate the oBRB and $\mathrm{iBRB}$, achieving appreciable concentrations in the retina and vitreous humor after systemic administration. The systemic application of drugs not only increases the quantity of a drug necessary to achieve therapeutic concentrations, but it also increases the risk of adverse effects due to the accumulation of a drug in other tissues throughout the body. Another limitation of systemic application includes potential reduced time of therapeutic effects and potency due to the dilution and degradation of the drug before reaching the target site. Despite these limitations, there have been advances in the use of systemic medications for the treatment of ophthalmic diseases.

To the wide sense, PDT with verteporfin is one of drug targeting systems. After intravenous administration, verteporfin, a relatively hydrophobic compound, is incorporated into lipoproteins. According to preferential accumulation of lipoproteins in and around choroidal neovascular membrane, verteporfin tends to be targeted into CNV. The photosensitizer targeted injures and closes new vessels in combination of laser irradiation to pathological lesion. However, most systemic drugs are now formulated with excipients that help overcome their tendency toward a brief duration of action and poor to medium bioavailability to the inner coat of the posterior segment.

One novel scheme to enhance the bioavailability of systemic drugs to the retina are penetration enhancers that help reversibly open up the BRB or improve transcellular penetration. Because TJ proteins are not very antigenic, it is difficult to develop antibodies against their extracellular domain, a fact that has severely hampered the development of TJ modulators. For example a novel approach to treat retinal disease by systemic drug delivery reviewed the role of the complement pathway in the pathogenesis of ARMD. Dysregulation of the alternate complement pathway, especially in the C3 amplification loop, may be a reasonable target for treating AMD and inflammatory retinal diseases by administering the 
intravenous fusion protein complement receptor 2 and factor $\mathrm{H}$ (CR2-fH), to recognize and inhibit complement- activation products (Holers, 2008; Rohrer, Long, Coughlin, et al. 2009; Thurman \& Holers, 2006). Complement receptor 2 recognizes C3d, a tissue-bound activation product of complementmediated inflammation (e.g., drusen), whereas the $\mathrm{fH}$ component of the fusion molecule is the most potent inhibitor of the alternative complement pathway. Some experimental studies have shown how the oxidative stress sensitizes RPE cells to complement-mediated attack by decreasing regulatory cell surface membrane-bound complement inhibitors to the alternative pathway.

That oxidative stress also alters RPE cells in such a way that soluble $\mathrm{fH}$ in the serum is less functionally protective (Thurman, Renner, Kunchithapautham, et al. 2009). Complementmediated attack of the RPE then results in sublytic activation of the membrane attack complex resulting in vascular endothelial growth factor VEGF release and breakdown of the oBRB (Thurman, Renner, Kunchithapautham, et al. 2009). In humans, this cascade of events can result in either dry geographic atrophy or wet AMD. Systemic CR2-fH therapy protects the retina using experimental mouse models of retinal degeneration and choroidal neovascularization.

\section{Conclusion}

Basic research and open clinical trials have provided breakthrough therapies for treatment of diseases of the posterior segment of the eye, such as the use of anti-VEGF agents for the treatment of AMD. More effective drugs and drug-delivery systems are needed to decrease the frequency of drug administration. Multiple drugs and drug delivery systems may be required to safely and successfully treat some conditions. However, effective treatment of posterior segment ophthalmic diseases represents a formidable challenge for scientists and clinicians in the ophthalmic pharmaceutical field. The challenges include the anatomic and physiologic barriers that can impede pharmacologically active levels of drug from reaching the targeted tissues inside the eye, immune reactions and clearance mechanisms to certain drugs and drug delivery materials, and the often irreversible nature of vision loss. A better understanding must be developed of the nature and effect of dynamic physiologic processes of the eye, such as clearance mechanisms and metabolism of drugs in specific tissue layers. Each static anatomic barrier encountered for each specific drug delivery technique must be better studied. Drug-protein or drug-pigment binding must be better characterized with needing of more research in formulation modifications that alter physicochemical properties of both new and old drugs, facilitating delivery through known paracellular and transcellular pathways. Ophthalmic drug delivery via nanotechnology-based products, development of ophthalmic gene delivery must be further explored, given the extensive potential of this technology. However a new "era" is coming, in which application of technological advances in vision science is progressing at a rapid rate. Advances in nanotechnology, gene therapy, and biomaterials, for example, hold promise for providing new solutions to the challenge of ocular drug delivery.

\section{References}

Acharya, N. \& Young, L. (2004). Sustained-release drug implants for the treatment ofintraocular disease. Int. Ophthalmol. Clin. 44:33-39. 
Amrite, A.C.; Edelhauser, H.F.; Singh, S.R. et al. (2008). Effect of circulation on thedisposition and ocular tissue distribution of $20 \mathrm{~nm}$ nanoparticles after periocular administration. Mol. Vis. 14:150-160.

Amrite, A.C. \& Kompella, U.B. (2005). Size-dependent disposition of nanoparticles andmicroparticles following subconjunctival administration. J. Pharm. Pharmacol. 57:1555-1563.

Andreoli, C.M. \& Miller, J.W. (2007). Anti-vascular endothelial growth factor therapy forocular neovascular disease. Curr. Opin. Ophthalmol. 18:502-508.

Aukunuru, J.V.; Ayalasomayajula, S.P. \& Kompella, U.B. (2003). Nanoparticle formulation enhances the delivery and activity of a vascular endothelial growth factor antisense oligonucleotide in human retinal pigment epithelial cells. J. Pharm. Pharmacol. 55:1199-1206.

Azadi, S.; Johnson, L.E.; Paquet-Durand, F. et al. (2007). CNTF+BDNF treatment and neuroprotective pathways in the rd1 mouse retina. Brain Res. , 1129, 116-129.

Ayalasomayajula, S.P. \& Kompella, U.B. (2003). Celecoxib, a selective cyclooxygenase-2 inhibitor, inhibits retinal vascular endothelial growth factor expression and vascular leakage in a streptozotocininduced diabetic rat model. Eur. J. Pharmacol. 458:283-289.

Ayalasomayajula, S.P. \& Kompella, U.B. (2004). Retinal delivery of celecoxib is several-fold higher following subconjunctival administration compared to systemic administration. Pharm. Res. 21:1797-1804.

Ayalasomayajula, S.P. \& Kompella, U.B. (2005). Subconjunctivally administered celecoxibPLGA microparticles sustain retinal drug levels and alleviate diabetes-induced oxidative stress in a rat model. Eur. J. Pharmacol. 511:191-198.

Barar, J.; Javadzadeh, A.R. \& Omidi. Y. (2008). Ocular novel drug delivery: impacts of membranes and barriers. Expert Opin. Drug Deliv. 5:567-581.

Barocas, V.H. \& Balachandran, R.K. (2008). Sustained transscleral drug delivery. Expert Opin. Drug Deliv. 5:1-10.

Bejjani, R.A.; BenEzra, D.; Cohen, H. et al. (2005). Nanoparticles for gene delivery to retinal pigment epithelial cells. Mol. Vis. 11:124-132.

Bekeredjian, R.; Katus, H.A. \& Kuecherer, H.F. (2006). Therapeutic use of ultrasound targeted microbubble destruction: a review of non-cardiac applications. Ultraschall. Med. 27:134-140.

Booth, B.A.; Denham, L.V.; Bouhanik, S.; et al. (2007). Sustained-release ophthalmic drug delivery systems for treatment of macular disorders: present and future applications. Drugs Aging. 24:581-602.

Bourges, J.L.; Gautier, S.E.; Delie, F. et al. (2003). Ocular drug delivery targeting the retina and retinal pigment epithelium using polylactide nanoparticles. Invest. Ophthalmol. Vis. Sci. 44:3562-3569.

Brown, D.M.; Kaiser, P.K.; Michels, M.; et al. (2006). ANCHOR Study Group. Ranibizumab versus verteporfin for neovascular age-related macular degeneration. $\mathrm{N}$ Engl J Med. 355:1432-44. 
Bu, H.Z.; Gukasyan, H.J.; Goulet, L. et al. (2007). Ocular disposition, pharmacokinetics, efficacy and safety of nanoparticle-formulated ophthalmic drugs. Curr. Drug Metab .8:91-107.

Callanan, D.G. (2007). Novel intravitreal fluocinolone acetonide implant in the treatment of chronic noninfectious posterior uveitis. Expert Rev Ophthalmol . 2: 33-44.

Carrasquillo, K.G.; Ricker, J.A.; Rigas, I.K. et al. (2003). Controlled delivery of the anti-VEGF aptamer EYE001 with poly(lactic-co-glycolic) acid microspheres. Invest. Ophthalmol. Vis. Sci. 44:290-299.

Chiang, C.H.; Tung, S.M. \& Lu, D.W. (2001). In vitro and in vivo evaluation of an ocular delivery system of 5-fluorouracil microspheres. J. Ocul. Pharmacol. Ther. 17:545553.

Choi, Y.K. \& Kim, K.W. (2008). Blood-neural barrier: its diversity and coordinated cell-to-cell communication. BMB Rep. 41:345-352.

ClinicalTrials.gov An exploratory study to evaluate the safety of brimonidine intravitreal implant in patients with retinitis pigmentosa. Available online: http://clinicaltrials.gov/ct2/show/ NCT00661479 (accessed on 18 October 2010).

ClinicalTrials.gov Fluocinolone acetonide intravitreal inserts in geographic atrophy.

Available online: http://clinicaltrials.gov/ct2/show/NCT00695318?term=Iluvien\&rank=15 (accessed on 18 October 2010).

ClinicalTrials.gov Safety and efficacy of brimonidine intravitreal implant in patients with geographic atrophy due to age-related macular degeneration (AMD). Available online: http://clinicaltrials.gov/ct2/show/NCT00658619 (accessed on 18 October 2010).

ClinicalTrials.gov The MAP Study: Fluocinolone acetonide (FA)/MedidurTM for age related macular degeneration (AMD) Pilot. Available online:

http://clinicaltrials.gov/ct2/show/NCT00605423?term=Iluvien\&rank=12 (accessed on 18 October 2010).

Craig, J. (2002). Structure and function of the preocular tear film. In The tear film; Korb, D.R., Craig, J., Doughty, M., Guillon, J., Smith, G., Tomlinson, A., Eds.; Butterworth-Heinemann: Oxford, UK. pp. 18-50Hoffman, A.S. (2008) The origins and evolution of 'controlled' drug delivery systems. J. Control. Release. 132:153163.

Cunha-Vaz, J. (1979). The blood-ocular barriers. Surv. Ophthalmol. 23, 279-296.

Del Amo, E.M. \& Urtti, A. (2008). Current and future ophthalmic drug delivery systems. A shift to the posterior segment. Drug Discov. Today. 13:135-143.

Eichler, W.; Kuhrt, H.; Hoffmann, S. et al. (2000). VEGF release by retinal glia depends on both oxygen and glucose supply. Neuroreport . 11, 3533-3537.

Farboud, B.; Aotaki-Keen, A.; Miyata, T. et al. (1999). Development of a polyclonal antibody with broad epitope specificity for advanced glycation endproducts and localization of these epitopes in Bruch's membrane of the aging eye. Mol. Vis. ; 5 , 11.

Fattal, E. \& Bochot, A. (2006). Antisense oligonucleotides, aptamers and SiRNA: promises for the treatment of ocular diseases. Arch. Soc. Esp. Oftalmol. 81:3-6. 
Fattal, E. \& Bochot, A. (2008). State of the art and perspectives for the delivery of antisense oligonucleotides and siRNA by polymeric nanocarriers. Int. J. Pharm. 364:237-248.

Fischbarg, J. (2006). The corneal endothelium. In The Biology of Eye; Fischbarg. J., Ed.; Academic Press: New York, NY, USA, pp. 113-125.

Gardner, T.W.; Lieth, E.; Khin, S.A. et al. (1997). Astrocytes increase barrier properties and ZO-1 expression in retinal vascular endothelial cells. Invest. Ophthalmol. Vis. Sci. $38,2423-2427$.

Gaudana, R.; Jwala, J.; Boddu, S.H.; et al. (2009) Recent perspectives in ocular drug delivery. Pharm. Res. 26:1197-1216.

Gausas,R.E.; Gonnering, R.S.; Lemke, B.N. et al. (1999). Identification of human orbital lymphatics. Ophthal. Plast. Reconstr. Surg. 15, 252-259.

Geroski, D.H \& Edelhauser, H.F. (2000). Drug delivery for posterior segment diseases. Invest Ophthalmol Vis Sci. 41:961-964.

Ghate, D. \& Edelhauser, H.F. (2006). Ocular drug delivery. Expert Opin. Drug Deliv. 3:275287.

Giese, K.; Kaufmann, J. \& Klippel-Giese, A. (2004) Future novel forms of interfering RNA molecules. WO2004015107.

Green, W.R. \& Enger, C. (1993). Age-related macular de generation histopathologic studies: the 1992 Lorenz E. Zimmerman Lecture. Ophthalmology. 100:1519-39.

Guidetti, B.; Azema, J.; Malet-Martino, M. et al. (2008). Delivery systems for the treatment of proliferative vitreoretinopathy: materials, devices and colloidal carriers. Curr. Drug Deliv . 5:7-19.

Handa, J.T.; Verzijl, N.; Matsunaga, H. et al. (1999). Increase in the advanced glycation end product pentosidine in Bruch's membrane with age. Invest. Ophthalmol. Vis. Sci. 40, 775-779.

Hayden, B.; Jockovich, M.E.; Murray, T.G. et al. (2006). Iontophoretic delivery of carboplatin in a murine model of retinoblastoma. Invest. Ophthalmol. Vis. Sci. 47:3713-3721.

Hewitt, A.T. \& Newsome, D.A. (1985). Altered synthesis of Bruch's membrane proteoglycans associated with dominant retinitis pigmentosa. Curr. Eye Res. 4, 169174.

Hewitt, A.T.; Nakazawa, K. \& Newsome, D.A. (1989). Analysis of newly synthesized Bruch's membrane proteoglycans. Invest. Ophthalmol. Vis. Sci. 30, 478486.

Higuchi, T. (1961). Release of medicaments from ointment bases containing drugs in suspension. J Pharm Sci . 50:874-875.

Holers, V.M. (2008). The spectrum of complement alternative pathwaymediated diseases. Immunol Rev. 223:300-316.

Hughes, P.M. Olejnik, O.; Chang-Lin, J.E. et al (2005). Topical and systemic drug delivery to the posterior segments. Adv. Drug Deliv. Rev. 57:2010-2032.

Hsu, J. (2007) Drug delivery methods for posterior segment disease. Curr. Opin. Ophthalmol. 18:235-239. 
Jager, R.D.; Aiello, L.P.; Patel, S.C. et al. (2004). Risks of intravitreous injection: a comprehensive review. Retina. 24:676-698.

Jiang, J.; Gill, H.S.; Ghate, D. et al. (2007). Coated microneedles for drug delivery to the eye. Invest Ophthalmol Vis Sci. 48:4038-4043.

Jiang, J.; Moore, J.S.; Edelhauser, H.F. et al. (2009). Instrsclera drug delivery to the eye using hollow microneedles. Pharm Res. ; 26:395-403.

Kaur, C.; Sivakumar, V. \& Foulds, W.S. (2006). Early response of neurons and glial cells to hypoxia in the retina. Invest. Ophthalmol. Vis. Sci. 47, 1126-1141.

Kearns, V.R. \& Williams, R.L. (2009). Drug delivery systems for the eye. Expert Rev. Med. Devices. 6(3): 277-290.

Kim, S.H.; Lutz, R.J.; Wang, N.S. et al. (2007). Transport barriers in transscleral drug delivery for retinal diseases. Ophthalmic Res. 39:244-254.

Kim, H.S.; Chang, Y.I.; Kim, J.H. et al. (2007). Alteration of retinal intrinsic survival signal and effect of alpha2-adrenergic receptor agonist in the retina of the chronic ocular hypertension rat. Vis. Neurosci. 24, 127-139.

Knight, C.G, ed. Liposomes: From Physical Structure to Therapeutic applications. Amsterdam: Elsevier/North Holland Biomedical Press, 1981.

Lee, S.J.; He, W.; Robinson, S.B. et al. (2010). Evaluation of clearance mechanisms with transscleral drug delivery. Invest. Ophthalmol. Vis. Sci. 51, 5205-5212.

Lee, S.S. \& Robinson, M.R. (2009). Novel drug delivery systems for retinal diseases. A review. Ophthalmic Res. 41:124-135.

Lemley, C.A. \& Han, D.P. (2007) Endophthalmitis: a review of current evaluation and management. Retina. 27:662-680.

Liu, M. \& Regillo, C.D. (2004). A review of treatments for macular degeneration: a synopsis of currently approved treatments and ongoing clinical trials. Curr. Opin. Ophthalmol. 15:221-226.

Lonngren, U.; Napankangas, U.; Lafuente, M. et al. (2006). The growth factor response in ischemic rat retina and superior colliculus after brimonidine pre-treatment. Brain Res. Bull. 71, 208-218.

Lyons, R.T.; Ma, H. \& Trogde, J.T. (2009). Methods, compositions and drug delivery systems for intraocular delivery of siRNA molecules. US20090258924.

Mannermaa, E.; Vellonen, K.S. \& Urtti, A. (2006). Drug transport in corneal epithelium and blood retina barrier: emerging role of transporters in ocular pharmacokinetics. Adv Drug Deliv Rev. 58:1136- 1163.

Maurice, D.M. \& Mishima, S. (1984). Ocular Pharmacokinetics. In: Pharmacology of the Eye. In: Sears ML, Ed. New York: Springer. 116-9.

McSwiggen, J.; Beigelman, L.; Macejak, D. et al. (2003) RNA interference by modified short interfering nucleic acid. WO2003070918 .

Mitra, A.K. (2009). Role of transporters in ocular drug delivery system. Pharm. Res. 26:11921196.

Moritera, T.; Ogura, Y.; Yoshimura, N. et al. (1994). Feasibility of drug targeting to the retinal pigment epithelium with biodegradable microspheres. Curr. Eye Res. 13:171-176. 
Moshfeghi, A.A. \& Peyman, G.A. (2005). Micro- and nanoparticulates. Adv. Drug Deliv. Rev. 57:2047- 2052.

Murakami, T.; Felinski, E.A. \& Antonetti, D.A. (2009). Occludin phosphorylation and ubiquitination regulate tight junction trafficking and vascular endothelial growth factor-induced permeability. J Biol. Chem. 284: 21036-21046.

Myles, M.E.; Neumann, D.M. \& Hill, J.M. (2005). Recent progress in ocular drug delivery for posterior segment disease: emphasis on transscleral iontophoresis. Adv. Drug Deliv. Rev. 57:2063-2079.

Novack, G.D. (2009). Ophthalmic drug delivery: development and regulatory considerations. Clin. Pharmacol. Ther. 85:539-543.

Okabe, K.; Kimura, H.; Okabe, J. et al. (2003). Intraocular tissue distribution of betamethasone after intrascleral administration using a non-biodegradable sustained drug delivery device. Invest Ophthalmol Vis Sci . 44: 2702-7.

Oyster, CW. (1999). The cornea and sclera. In The Human Eye; Oyster. C.W., Ed.; Sinauer Associates, Inc.: Sunderland, UK. pp. 325-378.

Pederson, J.E. (2006). Fluid physiology of the subretinal space. In Retina, Fourth edition; Ryan, S.J., Ed.; Elsevier Inc.: Philadelphia, PA, USA, Volume III, pp. 19091920.

Peppas, N.A. (1995). Controlling protein diffusion in hydrolgels. In: Lee VH-L, Hashida M, Misushima Y, eds. Trends and Future Perspectives in Peptide and Protein Delivery. Chur, Switzerland: Harwood Academic Publishers. :23-38.

Robinson, M.R.; Blanda, W.M.; Hughes, P.M. et al. (2010) Method for treating atrophic age related macular degeneration. US20100015158 \& WO2010009034 .

Robinson, M.R.; Blanda, W.M.; Liu, H. et al. (2010). Intraocular formulation. US20100074957.

Robinson, M.R.; Tsai, S.Y.; Almazan, A.S. et al. (2010). Drug delivery systems and methods for treating neovascularization. US20100098772 \& WO2010048086 .

Rohrer, B.; Long, Q.; Coughlin, B. et al. (2009). A targeted inhibitor of the alternative complement pathway reduces angiogenesis in a mouse model of age-related macular degeneration. Invest Ophthalmol Vis Sci. 50:3056-3064.

Rosenfeld, P.J.; Brown, D.M.; Heier, J.S.; et al. (2006). MARINA Study Group. Ranibizumab for neovascular age-related macular degeneration. N Engl J Med. 355: 1419-31.

Saishin, Y.; Silva, R.L.; Saishin, Y. et al. (2003). Periocular injection of microspheres containing PKC412 inhibits choroidal neovascularization in a porcine model. Invest. Ophthalmol. Vis. Sci. 44:4989-4993.

Sakurai, E.; Ozeki, H.; Kunou, N. et al. (2001). Effect of particle size of polymeric nanospheres on intravitreal kinetics. Ophthalmic Res. 3:31-36.Tanito, M.; Li, F.; Elliott, M.H. (2007). Protective effect of TEMPOL derivatives against light-induced retinal damage in rats. Invest. Ophthalmol. Vis. Sci. 48:1900-1905.

Sarks, SH. (1976). Ageing and degeneration in macular region: a clinicopathological study. Br J Ophthalmol. 60:324-41.

Singh, D. (2003). Conjunctival lymphatic system. J. Cataract. Refract. Surg. 29, 632-633. 
Spaide, RF. (2009). Enhanced depth imaging optical coherence tomography of retinal pigment epithelial detachment in age-related macular degeneration. Am. J. Ophthalmol. 147, 644-652.

Spraul, C.W.; Lang, G.E.; Grossniklaus, H.E. et al. (1999). Histologic and morphometric analysis of the choroid, Bruch's membrane, and retinal pigment epithelium in postmortem eyes with age-related macular degeneration and histologic examination of surgically excised choroidal neovascular membranes. Surv. Ophthalmol. 44 Suppl 1, S10-32.

Sugar, H.S.; Riazi, A. \& Schaffner, R. (1957). The bulbar conjunctival lymphatics and their clinical significance. Trans. Am. Acad. Ophthalmol. Otolaryngol., 61, 212-223.

Sultana, Y.; Jain, R.; Aqil, M.; et al. (2006) Review of ocular drug delivery. Curr. Drug Deliv. 3:207-217.

Thurman, J.M. \& Holers, V.M. (2006). The central role of the alternative complement pathway in human disease. J Immunol. 176:1305-1310.

Thurman, J.M.; Renner, B.; Kunchithapautham, K. et al. (2009). Oxidative stress renders retinal pigment epithelial cells susceptible to complement-mediated injury. J Biol Chem. 284:16939-16947.

Tout, S.; Chan-Ling, T.; Hollander, H. et al. (1993). The role of Muller cells in the formation of the blood-retinal barrier. Neuroscience. 55, 291-301.

Tretiach, M.; Madigan, M.C.; Wen, L. et al. (2005). Effect of Muller cell co-culture on in vitro permeability of bovine retinal vascular endothelium in normoxic and hypoxic conditions. Neurosci. Lett. 378, 160-165.

Tsutomu, Y.; Yasuhiko, T.; Hideya, K. et al. (2011). Recent Advances in Intraocular Drug Delivery Systems. Recent Patents on Drug Delivery \& Formulation. 5(1): 1-10.

Tuovinen, L.; Ruhanen, E.; Kinnarinen, T. et al. (2004). Starch acetate microparticles for drug delivery into retinal pigment epithelium-in vitro study. J. Control. Release ;98:407413.

Van der Schaft, T.L.; de Bruijn, W.C.; Mooy, C.M.; et al. (1992). Histologic features of the early stages of age-related macular degeneration: a statistical analysis. Ophthalmology. 99:278-86.

US National Institutes of Health. ClinicalTrials.org. NCT00447954 CgI. A Study of an Encapsulated Cell Technology (ECT) Implant for Patients With Atrophic Macular Degeneration. Phase II study. 2009. http://clinicaltrials.gov/ct2/show/NCT00447954. Accessed December 24,2009.

Zhang, M.; Mo, X; Fang, Y. et al. (2009). Rescue of photoreceptors by BDNF gene transfer using in vivo electroporation in the RCS rat of retinitis pigmentosa. Curr. Eye Res. 34, 791-799.

Zhang, Y. \& Stone, J. (1997). Role of astrocytes in the control of developing retinal vessels. Invest. Ophthalmol. Vis. Sci. 38, 1653-1666. 
Yamada, Y.; Ishibashi, K.; Bhutto, I.A. et al. (2006). The expression of advanced glycation endproduct receptors in rpe cells associated with basal deposits in human maculas. Exp. Eye Res. 82, 840-848.

Yasukawa, T.; Ogura, Y.; Kimura, H. et al. (2006). Drug delivery from ocular implants. Expert Opin Drug Deliv . 3: 261-73.

Yasukawa, T.; Ogura, Y.; Tabata, Y. et al. (2004). Drug delivery systems for vitreoretinal diseases. Prog Retin Eye Res . 23: 253-81. 


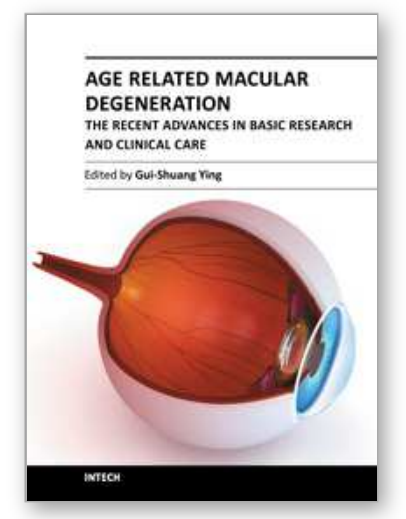

\author{
Age Related Macular Degeneration - The Recent Advances in Basic \\ Research and Clinical Care \\ Edited by Dr. Gui-Shuang Ying
}

ISBN 978-953-307-864-9

Hard cover, 300 pages

Publisher InTech

Published online 20, January, 2012

Published in print edition January, 2012

Age-related Macular Degeneration (AMD) is the leading cause of vision loss and blindness in the developed countries. In the past decade, great progress has been made in understanding the pathobiology and genetics of this blinding disease, as well as in finding new therapies for its treatment. These include the discovery of several genes that are associated with the risk of AMD, new anti-VEGF treatments for wet AMD and new imaging techniques to diagnose and monitor the AMD. All chapters in this book were contributed by outstanding research scientists and clinicians in the area of AMD. I hope this timely book will provide the basic scientists and clinicians with an opportunity to learn about the recent advances in the field of AMD.

\title{
How to reference
}

In order to correctly reference this scholarly work, feel free to copy and paste the following:

Giuseppe Lo Giudice and Alessandro Galan (2012). Basic Research and Clinical Application of Drug Delivery Systems for the Treatment of Age-Related Macular Degeneration, Age Related Macular Degeneration - The Recent Advances in Basic Research and Clinical Care, Dr. Gui-Shuang Ying (Ed.), ISBN: 978-953-307-864-9, InTech, Available from: http://www.intechopen.com/books/age-related-macular-degeneration-the-recentadvances-in-basic-research-and-clinical-care/drug-delivery-systems-for-the-treatment-of-age-related-maculardegeneration-

\section{INTECH}

open science | open minds

\author{
InTech Europe \\ University Campus STeP Ri \\ Slavka Krautzeka 83/A \\ 51000 Rijeka, Croatia \\ Phone: +385 (51) 770447 \\ Fax: +385 (51) 686166 \\ www.intechopen.com
}

\author{
InTech China \\ Unit 405, Office Block, Hotel Equatorial Shanghai \\ No.65, Yan An Road (West), Shanghai, 200040, China \\ 中国上海市延安西路65号上海国际贵都大饭店办公楼405单元 \\ Phone: +86-21-62489820 \\ Fax: +86-21-62489821
}


(C) 2012 The Author(s). Licensee IntechOpen. This is an open access article distributed under the terms of the Creative Commons Attribution 3.0 License, which permits unrestricted use, distribution, and reproduction in any medium, provided the original work is properly cited. 